\title{
Influence of curing conditions on durability of alkali-resistant glass fibres in cement matrix
}

\author{
ARABI NOURREDINE \\ Laboratoire de Génie Civil, Université de Annaba, BP 12 Annaba 23000, Algérie
}

MS received 16 October 2009; revised 13 July 2010

\begin{abstract}
Glass fibres in concrete material often increase the flexural strength. However, these fibres when in contact with cement are altered by alkali reactions due to the presence of portlandite. This study presents the results of investigation to show the effect of curing conditions on the durability of alkali-resistant glass fibres in cement matrix. Test results show that even alkali resistant fibres treated with zirconium oxide present the same degradation phenomenon. They also show that the nature of the cement has a large influence on the protection of the fibres: the Portland CEM II is less damaging than the CEM I. The substitutions of a part of cement by silica fume gave no substantial improvements to the mechanical strength of the glass fibre reinforced cement (GFRC). However, the observed microstructures in the samples show that the degradation is weakened with the addition of silica fumes. The analytical techniques used in this study are scanning electron microscope (SEM) and X-ray diffraction.
\end{abstract}

Keywords. Glass fibre; cement matrix; durability; curing conditions; silica fume.

\section{Introduction}

The studies on the glass fibre reinforced cement (GFRC) showed the low durability of the fibres in the cement matrix (Daniel and Schultz 1986; Majumbar and Walton 1991; Graham 2004; Bentur and Mindess 2007). Alkali resistant glass fibres, called CemFil, have been developed using zirconium oxide $\left(\mathrm{ZrO}_{2}\right)$ additives that inhibit the cement matrix attacks. However, they are still sensitive to a humid environment; i.e. a decrease in the flexural strength is usually observed (Kosa et al 1991; Xu et al 1998). The degradation of strongly siliceous fibres is a result of the composite internal behaviour where the cimentitious matrix constitutes an aggressive environment. Although the causes of this phenomenon are still not well known, chemical and physical factors were highlighted to describe the loss of resistance and ductility of the composite in humid environments.

Charles (1958) pointed out that glass corrosion constitutes the chemical factor of the glass dissolution in humid environments. This study suggest that only the terminal end, which associates $\mathrm{Na}^{+}$ion to the glass network, is responsible for dissolution. This initial dissolution or 'leaching' occurs according to (1). Therefore, the more alkaline is added to the bulk of the glass structure, the more it becomes chemically reactive in humid environments

(nourredine_arabi@yahoo.fr)

$$
\left[\begin{array}{l}
! \\
\stackrel{\mathrm{Si}}{!}-\mathrm{O}-\mathrm{Na}
\end{array}\right]+\mathrm{H}_{2} \mathrm{O} \rightarrow-\underset{!}{\mathrm{SiOH}}+\mathrm{Na}^{+}+\mathrm{OH}^{-}
$$

The oxygen-sodium bond near the interface is broken by the removal of the $\mathrm{Na}^{+}$ion and the remaining oxygen atom captures the hydrogen ion $\mathrm{H}^{+}$. This causes additional stress on the glass surface because the $\mathrm{H}^{+}$ion is larger than the $\mathrm{Na}^{+}$and hence producing cracks, especially under the effect of the tensile forces. These cracks can get larger and propagate into the inner parts, resulting in the failure of the specimen. Free hydroxyl ion is formed in the process and enables the second reaction, (2), to take place

$$
\left[\begin{array}{cc}
! & ! \\
-\mathrm{Si}-\mathrm{O}-\mathrm{Si}- & !
\end{array}\right]+\mathrm{OH}^{-} \rightarrow-\underset{!}{\mathrm{Si}}-\mathrm{O}-\mathrm{H}+\underset{!}{\stackrel{\mathrm{SiO}^{-}}{!}}
$$

The $\mathrm{SiO}^{-}$which is one of the by-products of the previous equation can dissociate another water molecule as shown in (3) and the $\mathrm{SiOH}$ by-product forms a gel on the surface of the bar, slowing down the process

$$
\left[\begin{array}{c}
! \\
-\mathrm{SiO}^{-} \\
!
\end{array}\right]+\mathrm{H}_{2} \mathrm{O} \rightarrow-\underset{!}{\mathrm{SiOH}}+\mathrm{OH}^{-} .
$$

As seen from the above three equations, the excess of hydroxyl ions production will increase the $\mathrm{pH}$ of the solution. From (4), it is clear that these ions attack the fibre surface resulting in flaws that significantly degrade strength and can result in premature fracture and failure 
of the fibres (Gonenc 2003). This reaction can also occur during the dissolution of the glass in water

$$
\left[\begin{array}{c}
! \\
-\mathrm{Si}-\mathrm{O}-\mathrm{Si}- \\
!
\end{array}\right]+\mathrm{H}_{2} \mathrm{O} \rightarrow 2\left[\begin{array}{c}
! \\
-\mathrm{Si}-\mathrm{O}-\mathrm{H} \\
!
\end{array}\right] .
$$

However, since the glass structure has many terminal ends, the occurrence of the first three equations is much more probable.

The chemical reactions that cause glass fibre degradation are also function of alkalinity, degree of moisture, diffusivity, and void ratio (Schutte, 1994). Furthermore, the physical factor of glass fibre degradation is a result of the portlandite $\left[\mathrm{Ca}(\mathrm{OH})_{2}\right]$ deposition and growth. Portlandite is formed during the cement hydration that fills spaces between and around the glass fibre filaments, thus, cementing them together and reducing their flexibility. This causes excessive bonding and local concentration of stresses under load at the surface of fibres, resulting in embrittlement of GFRC (Hayashi et al 1985; Purnell et al 1999).

Several techniques are used to protect fibres. One of these is to protect the fibres either by using a low alkalinity cement (Marikunte et al 1997; Purnell et al 2000; Krüger et al 2003; Péra and Ambroise 2003; Cuypers et al 2006) or by densifying the interface between fibres and matrix with polymers (PVA, AC or VAC) to prevent the lime diffusion into the fibres (Rols et al 2000; Li et al 2002). Another technique consists in limiting the alkalisilica reaction by reducing the amount of portlandite into the matrix under pozzolanic effect. For instance, fly ashes, silica fumes or granulated blast furnace slag could be added to conventional concrete in order to substitute a part of the cement (Gudmundsson and Olafsson 1999; Shehata and Thomas 2000; Paya et al 2007).

The aim of this study is to analyze the behaviour of fibres in the cement matrix with or without silica fume addition under different storage conditions. The fibres are observed by scanning electron microscopy (SEM) and the portlandite is quantified by X-ray diffraction.

\section{Experimental}

\subsection{Materials}

2.1a Matrix materials: The CEM II/B 32.5R and CEM I 52.5 were the two types of cements used in this study and manufactured by Ciment Lafarge Ltd (France), conform to EN 196.1 (the European standard). Their chemical composition is given by the manufacturer and presented in table 1. Also, the sand used was a siliceous fraction that did not exceed $500 \mu \mathrm{m}$ in size. Silica fume (a byproduct of the semiconductor industry brought from Bretagne area in France) was added for a series so as to reduce the amount of portlandite by pozzolanic effect (table 3). The silica fume fraction varied between 30 and
$100 \mathrm{~nm}$ in size and its chemical composition is given in table 1. To improve the fresh mixture workability, the superplasticiser Sikament FF86, conform to NF 9342 (French standard) was added.

2.1b Fibers: The studied glass fibres were alkali resistant (A-R glass fibres), from Saint Gobain Vetrotex manufacturer. The fibres (12 $\mathrm{mm}$ in length) were $\mathrm{ZrO}_{2}-$ rich (16.6 weight \%) and this could protect the fibres from the alkaline attacks of the cement matrix. The main physical and mechanical properties of these fibres are shown in table 2 .

\subsection{Sample preparation and tests}

Six samples of glass fibre reinforced matrix mixtures of $4 \times 4 \times 16 \mathrm{~cm}^{3}$ were prepared and their composition is given in table 3 . Samples 1-3 were prepared with CEM II/B 32.5 cement and samples $4-6$ with CEM I 52.5. The rate of silica fume added to samples 1-3 was very low (3\%) since the CEM II/B 32.5 cement contained already $24 \mathrm{wt} \%$ fly ash. On the other hand, the amount of silica fumes added to samples 4-6 was limited to 5\% for comparison.

The glass fibre reinforced matrix samples were removed from mould after $24 \mathrm{~h}$. They were conserved in moist room (temperature of $20^{\circ} \mathrm{C}$ and humidity of $95 \%$ ) for 7 days, then maintained in different environments for one year: either in moist room $\left(T=20^{\circ} \mathrm{C}\right.$, humidity $=95 \%$ ), in air conditioned room considered as dry

Table 1. Chemical composition (weight \%) of the cements and of the silica fumes: according to the manufacturer.

\begin{tabular}{|c|c|c|c|}
\hline $\begin{array}{l}\text { Composition } \\
\text { (wt.\%) }\end{array}$ & $\begin{array}{c}\mathrm{CEM} \mathrm{II/B} \\
32.5 \mathrm{R}\end{array}$ & $\begin{array}{l}\text { CEM } \\
\text { I } 52.5\end{array}$ & $\begin{array}{l}\text { Silica } \\
\text { fume }\end{array}$ \\
\hline $\mathrm{SiO}_{2}$ & $25 \cdot 05$ & $19 \cdot 7$ & $97 \cdot 64$ \\
\hline $\mathrm{Al}_{2} \mathrm{O}_{3}$ & $8 \cdot 6$ & $4 \cdot 9$ & \\
\hline $\mathrm{Fe}_{2} \mathrm{O}_{3}$ & $3 \cdot 5$ & $2 \cdot 8$ & $0 \cdot 1$ \\
\hline $\mathrm{CaO}$ & $55 \cdot 4$ & $64 \cdot 5$ & $0 \cdot 14$ \\
\hline $\mathrm{MgO}$ & $0 \cdot 9$ & $0 \cdot 9$ & $0 \cdot 15$ \\
\hline $\mathrm{K}_{2} \mathrm{O}$ & 1 & $0 \cdot 9$ & $0 \cdot \cdot 39$ \\
\hline $\mathrm{Na}_{2} \mathrm{O}$ & $0 \cdot 15$ & $0 \cdot 2$ & $0 \cdot 14$ \\
\hline $\mathrm{SO}_{3}$ & $2 \cdot 7$ & 3 & \\
\hline $\mathrm{S}^{-}$ & $<0.01$ & $<0 \cdot 01$ & \\
\hline $\mathrm{Cl}^{-}$ & $0 \cdot 022$ & $0 \cdot 01$ & \\
\hline Insoluble & $11 \cdot 8$ & $0 \cdot 2$ & \\
\hline Loss on ignition & $2 \cdot 2$ & $2 \cdot 7$ & \\
\hline $\mathrm{TiO}_{2}$ & - & - & \\
\hline $\mathrm{MnO}$ & - & - & \\
\hline $\mathrm{P}_{2} \mathrm{O}_{5}$ & - & - & \\
\hline $\mathrm{Mn}_{2} \mathrm{O}_{3}$ & - & - & \\
\hline Undosed & $0 \cdot 468$ & $0 \cdot 38$ & \\
\hline Total & 100 & 100 & \\
\hline $\mathrm{CO}_{2}$ & 1 & 1.9 & \\
\hline Free $\mathrm{CaO}$ & $1 \cdot 2$ & 1.4 & \\
\hline Active alkalines & 0.75 & - & \\
\hline Gypsum content & 5 & 5 & \\
\hline
\end{tabular}


Table 2. Physical and mechanical properties of AR glass fibre.

\begin{tabular}{ll}
\hline Properties & \\
\hline Density & $2 \cdot 68 \mathrm{~g} / \mathrm{cm}^{3}$ \\
Tensile strength: virgin filament & $3000 \mathrm{MPa}$ \\
Tensile modulus & $73000 \mathrm{MPa}$ \\
Elongation at break & $4 \cdot 30 \%$ \\
Coefficient of linear thermal expansion (between 20 and $\left.100^{\circ} \mathrm{C}\right)$ & $5 \cdot 10^{-6} \mathrm{~m} / \mathrm{m} / \mathrm{K}$ \\
Flammability & $773^{\circ} \mathrm{C}$ \\
\hline
\end{tabular}

Table 3. Compositions of the used mortar series.

\begin{tabular}{lllllllll}
\hline & \multicolumn{3}{c}{ CEM II/B 32.5R } & & \multicolumn{3}{c}{ CEM I 52.5 } \\
\cline { 2 - 4 } \cline { 7 - 8 } Constituents (weight \%) and ratios & 1 & 2 & 3 & & 4 & 5 & 6 \\
\hline Cement/sand & 1 & 1 & 1 & & 1 & 1 & 1 \\
Water/cement & $0 \cdot 35$ & $0 \cdot 35$ & $0 \cdot 35$ & & $0 \cdot 35$ & $0 \cdot 35$ & $0 \cdot 35$ \\
Fibres & 0 & 2 & 2 & & 0 & 2 & 2 \\
Silica fumes & 0 & 0 & 3 & & 0 & 0 & 5 \\
Superplasticizer & 0 & 0 & 2 & & 0 & 0 & 2 \\
\hline
\end{tabular}

Table 4. Samples formulations and storage conditions.

\begin{tabular}{llccl}
\hline Used cement & Samples & Fiber rates (weight \%) & Silica fume (weight \%) & Storage conditions \\
\hline CEM II & FSH2 & 2 & - & Moist room \\
& FCA2 & 2 & - & Ambient air \\
& FSH3 & 2 & 3 & Moist room \\
& FCA3 & 2 & 3 & Ambient air \\
& FSC2 & 2 & - & Dry environment \\
\multirow{3}{*}{ CEM I } & FSC3 & 2 & 3 & Dry environment \\
& FSH4 & 2 & - & Moist room \\
& FSH5 & 2 & 5 & Moist room \\
& FCA5 & 2 & 5 & Ambient air \\
\hline
\end{tabular}

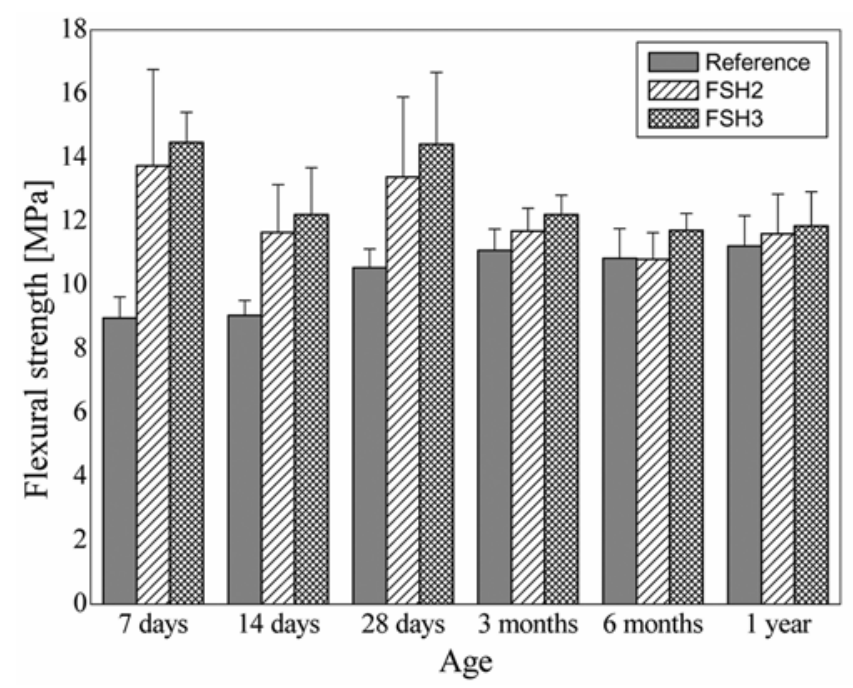

Figure 1. Flexural strength development in moist room curing.

environment $\left(T=20^{\circ} \mathrm{C}\right.$, humidity $\left.=50 \%\right)$, or in ambient air conditions. The sample formulations and conservations are given table 4 .

The flexural strength (four-point loading test) was measured at periods of $7,14,28,90,180$ and 360 days. Each value represented the average of 6 tests.
The $\mathrm{pH}$ of pore solutions were determined after one year of storage by a $\mathrm{pH}$-meter. The tests were carried out on diluted solutions where the ratio of solid/demineralised water was $1 / 10$ and the temperature is $20^{\circ} \mathrm{C}$.

The phase composition of each sample was determined by X-ray diffraction (XRD) and the microstructures were examined using both a scanning electron microscope (SEM field effect) and an energy dispersive X-ray analysis (EDX) coupled with a conventional microscope.

\section{Results and discussion}

\subsection{Environment effect on the mechanical resistance}

From figures 1-3 that show the flexural strength behaviour of cement CEM II $32.5 \mathrm{R}$ with age in moist room, ambient air, and dry environment conditions, it is clear that there is a marked reduction in flexural strength for all the samples reinforced by A-R glass fibres in the three conservation mediums. Also, in the same conditions, statistical data analyses of flexural strength show a rather high dispersion of the fibre-containing samples than that of the reference samples (i.e. without fibres). This dispersion seems to be related to the effect of the randomly dis- 
tributed fibres which make the matrix more heterogeneous. It is also noticed that between the 7th and the 14th day, there is a marked drop of flexural strength in the fibre-containing samples followed by a subsequent increase on 28th day within the three medium conditions. This drop of flexural strength is explained by the alkaline attack of cement at the surface of the fibre beams after 14 days of conservation. Figure 4 shows that the fibres in contact with the matrix are highly corroded, while the fibres which are not in contact with the matrix are not very altered. On these last fibres, some small and scattered pittings are visible. The protective layer of fibres seems to be strongly affected by the alkaline attack which probably have a major effect on the interface, and consequently on the fibre-matrix bond. Figure 4 also shows

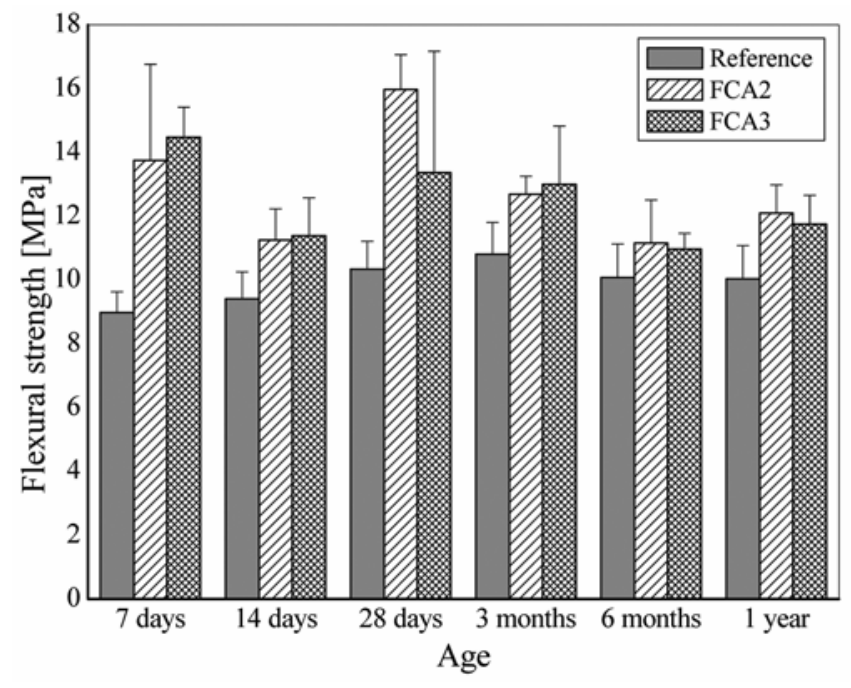

Figure 2. Flexural strength development in ambient air curing.

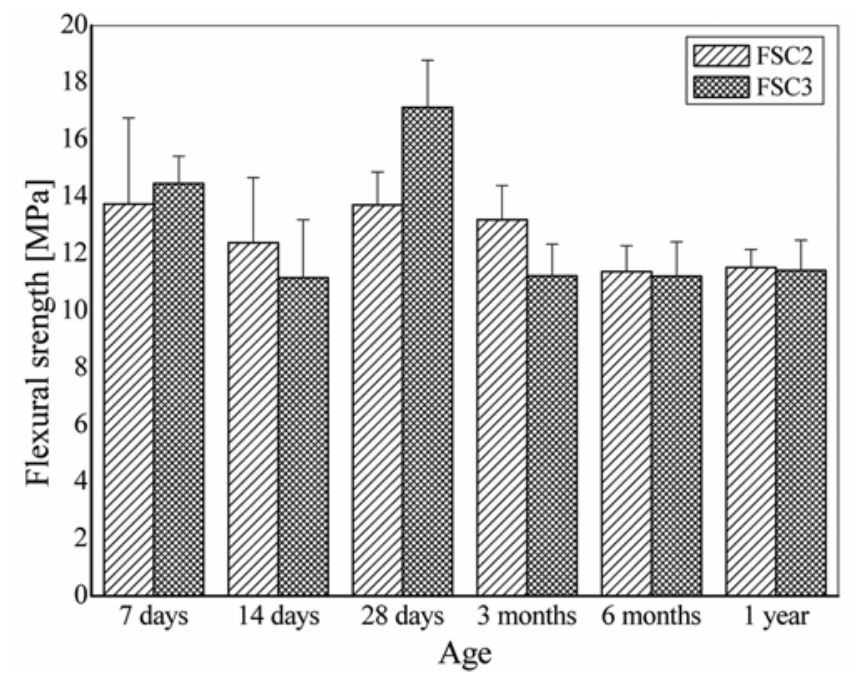

Figure 3. Flexural strength development in dry environment curing. that the matrix has not yet acquired a perfect compact structure. The increase in strength in 28 days could be attributed to the development of a proper bond between fibres and cement matrix. Afterwards, the flexural strength decreases gradually until the 90th day of testing. This drop of flexural strength is attributed to the diffusion of the calcium hydroxide into the spaces between fibres as shown in figure 5 . This was reported by many authors (Hayashi et al 1985; Purnell et al 1999). Two modes of attack on the glass fibres are evident: hydroxylation and notching by $\mathrm{Ca}(\mathrm{OH})_{2}$ crystals. The surface of fibres becomes generally hydroxylated due to the high $\mathrm{pH}$ of the matrix, but notching attack is concentrated at points where a fibre is in good contact with $\mathrm{Ca}(\mathrm{OH})_{2}$ crystals,

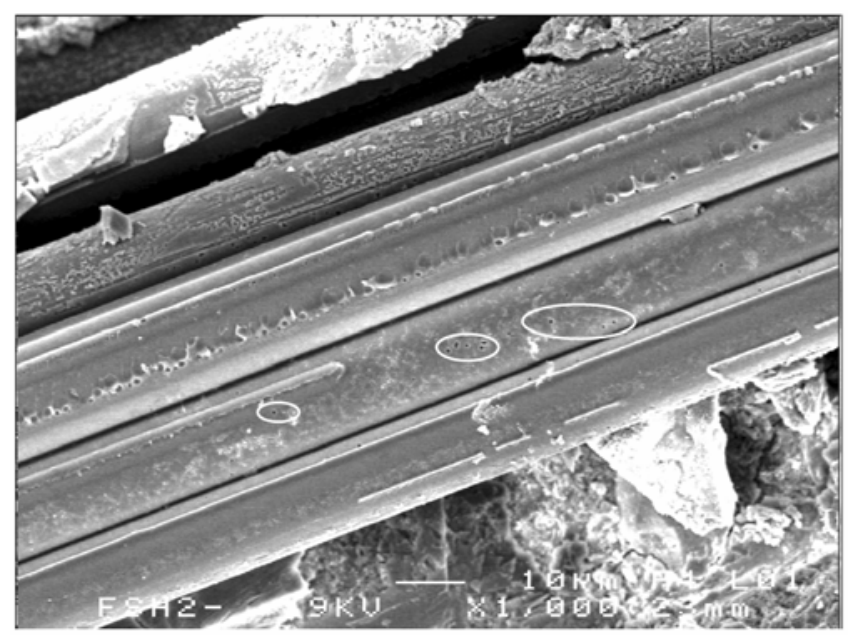

Figure 4. Effect of alkaline attack on $A R$ glass fibres in cement matrix after 14 days of conservation (top-left-hand side). Note that in the middle of the figure the fibres are not very altered.

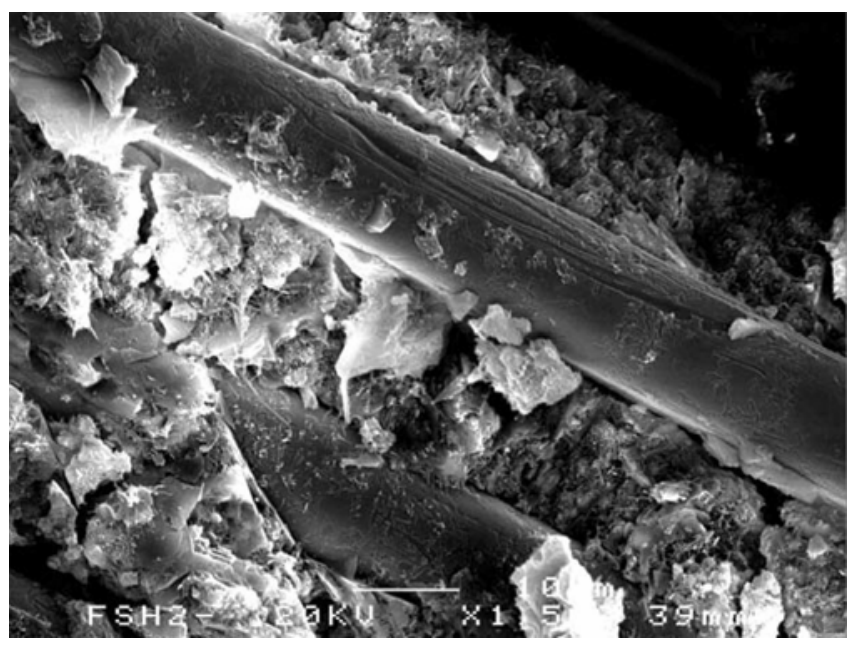

Figure 5. Alkali-resistant glass fibres in cement matrix after 90 days. Filling of the spaces between the filaments by calcium hydroxide. Note surface corrosion and notching by $\mathrm{Ca}(\mathrm{OH})_{2}$. 
leading to their impingement on and into fibres (Yilmaz and Glasser 1992).

For the three conservation conditions, a drop of flexural strength in fibre-containing samples is observed between the 28th and 90th day; but after the 6th month, flexural strength seems to stabilize but shows a slight increase for some conservation conditions. Although there are significant reductions in strength of the GFRC after one year of hardening, the flexural strength values show that these composites tend always to give better performances in flexure than does of the reference sample.

Figures 6 and 7 show the evolution of flexural strength of the fibre-containing samples with and without silica fume under three curing conditions. The substitution of cement CEM II 32.5 at the rate of $3 \%$ by the silica fume, to reduce the alkalinity of cement and to protect A-R glass fibres from the attacks modes, gave no substantial improvements in resistances gain and also did not preserve the mechanical resistance obtained at the first month of hardening. Moreover, the inclusion of a mineral

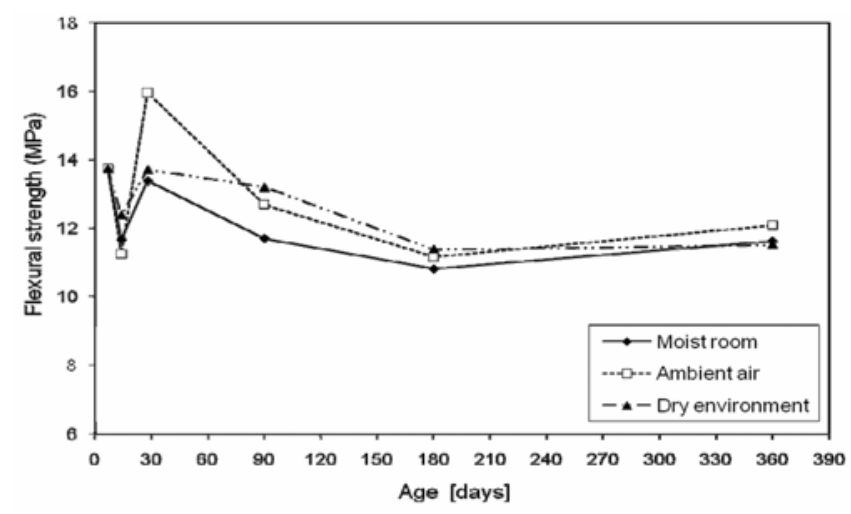

Figure 6. Flexural strength development under various mediums of conservation for samples containing $2 \%$ fibre.

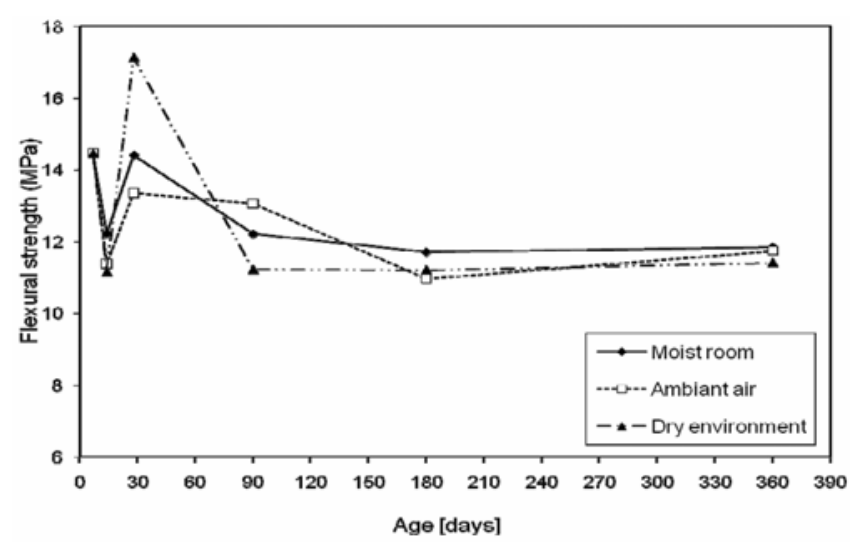

Figure 7. Flexural strength development under various mediums of conservation for samples containing 2\% fibre and $3 \%$ silica fume. addition such as the silica fume has a slow reaction effect with calcium hydroxide (pozzolanic effect), whereas the kinetics of degradation of glass fibres occur earlier. The effect of silica fume seems to appear after the 6th month of conservation. This effect is observed only for the samples conserved in moist room. It is evident that the pozzolanic effect is favoured by the presence of the interstitial solution in the porosity of the samples in high wet conditions. It should be noted that the addition of silica fume is beneficial at the interface where it is most needed to delay or prevent the development of portlandite formation. However, if the silica fume with very fine particle size $(<0 \cdot 1 \mu \mathrm{m})$ penetrate the interfilament spaces where the free lime deposition mechanism has taken place and become even harder. This results in a more damaging $\mathrm{CSH}$ within the fibre bundle.

The samples conserved between 6 months and 1 year at ambient air and in dry environment have shown an improved flexural strength. The improvement in strength beyond 6 months is probably due to the portlandite transformation into calcite. This is accompanied by an increase in crystalline volume which results in a decreasing porosity of the cement paste. This can only limit the diffusion of the calcium hydroxides in the inter-fibre spaces as is pointed out by some authors (Purnell et al 2000, 2003). This hypothesis of carbonation supposes that the portlandite was not consumed completely by the silica fume, due probably to the lack of interstitial solution in the pores of the matrix to initiate the pozzolanic effect between the portlandite and the silica fume.

In this article, the flexural strength of CEM I 52.5 cement is not the subject of a comparison with cement CEM II $32 \cdot 5 \mathrm{R}$ which are different cement types. The comparison is made only on observations by scanning electron microscopy.

\subsection{Quantitative analysis of portlandite}

The X-ray diffraction ( $\lambda \mathrm{K}_{\alpha} \mathrm{Cu}$, Ni filter, step to step) has been performed on four samples: FSH2 and FSH3 conserved in moist room, FCA2 and FCA3 conserved at ambient air. The X-ray patterns are given in figure 8 . The peak intensity of the calcium hydroxide (portlandite) on the diffraction pattern is measured by the integrated method; results are reported on table 5. It also shows the peak intensity of the calcium carbonate (calcite) in order to underline the carbonation of the samples.

The intensity of the portlandite related peaks is lower for the FCA samples, conserved at ambient air, than for the FSH samples conserved in moist room. The development of the portlandite crystals in FSH samples can be explained by the presence of water on the porosity of the samples. The water permits the $\mathrm{Ca}^{++}$ions diffusion towards the matrix and then the growth of the portlandite crystals (Olafsson 1986; Kurihara and Katawaki 1989; 

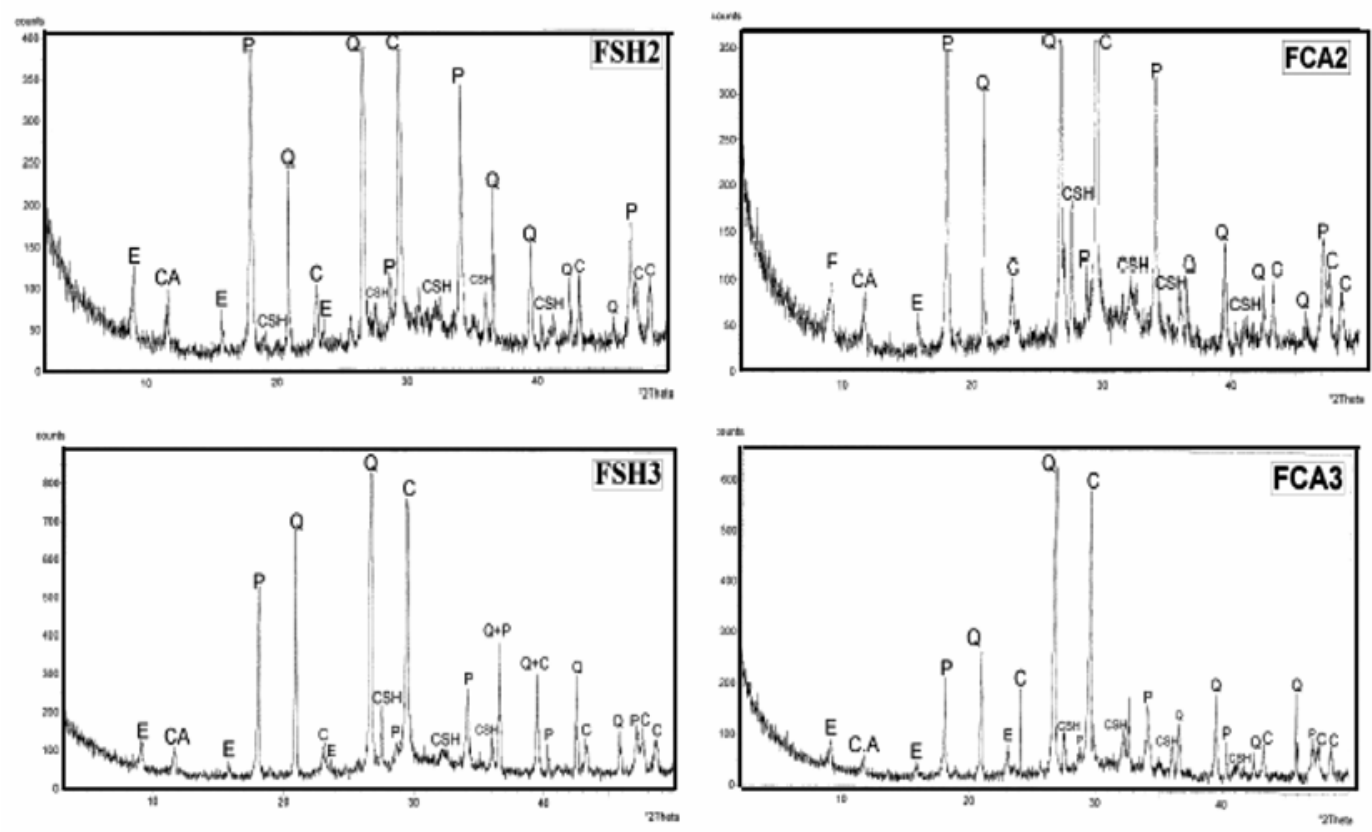

Figure 8. X-ray diffraction patterns $(\lambda \mathrm{K} \alpha \mathrm{Cu})$. Q, quartz; P, portlandite $\left(\mathrm{Ca}(\mathrm{OH})_{2}\right)$; , calcite $\left(\mathrm{CaCO}_{3}\right)$; E, Ettringite; $\mathrm{CSH}$, calcium silicate hydrates; and $\mathrm{CA}$, calcium carboaluminate.

Table 5. X-ray diffraction peaks intensity of the calcium hydroxide and the calcite.

\begin{tabular}{lllrrrr}
\hline & \multicolumn{7}{c}{ Formulations } \\
\cline { 2 - 7 } & $2 \theta$ & $d(\AA)$ & FSH2 & FSH3 & FCA2 & FCA3 \\
\hline Calcium hydroxide $\left[\mathrm{Ca}(\mathrm{OH})_{2}\right]$ & $18 \cdot 08$ & 4.90 & 995 & 504 & 603 & 171 \\
& $34 \cdot 1$ & 2.62 & 305 & 202 & 291 & 146 \\
& $47 \cdot 13$ & 1.93 & 125 & 103 & 114 & 62 \\
Calcite $\left[\mathrm{CaCO}_{3}\right]$ & $23 \cdot 11$ & 3.84 & 65 & 87 & 70 & 48 \\
& $29 \cdot 45$ & 3.02 & 542 & 728 & 639 & 517 \\
& $47 \cdot 62$ & 1.90 & 67 & 95 & 69 & 61 \\
\hline
\end{tabular}

Tomasawa et al 1989). Portlandite peaks are weaker in the samples containing silica fume. This confirms a reaction between portlandite and silica, and thus the expected pozzolanic effect.

The carbonation phenomenon is observed in all the samples, regardless of the conservation environments, but is limited when samples are conserved in moist room because water in pores prevents the $\mathrm{CO}_{2}$ penetration into the matrix. However, the carbonate is developed in the near surface matrix and comes from the portlandite transformation into calcite. This transformation is accompanied by an increase of the crystal volume that induces a decrease of the cement matrix porosity in the near surface. As mentioned by different authors (Purnell et al 2000, 2003), the carbonation limits the growth of portlandite by decreasing the diffusions in the porosity.

\subsection{Microstructural observations}

The SEM observations are displayed in figure 9 and concern matrixes made of CEM II/B 32.5. The first micrograph displays the aspect of the A-R glass fibre before mixing: a regular and smooth surface. FSH2 and FSH3 samples, conserved in moist room, present a strong degradation of the fibres, with attack spots observed along the surface. However, the actual degradations are superficial and not homogeneous. It is noted that fibres are less damaged in the FSH3 samples due to the silica fume additions. The energy dispersive X-ray (EDX) analysis of the A-R glass fibre surface support the observed results. The localized chemical analysis realized on two different points (table 6) shows a degradation of the silicic network of the glass fibre. At point A, in the FSH3, there is no degradation of the fibre body and the microanalysis 

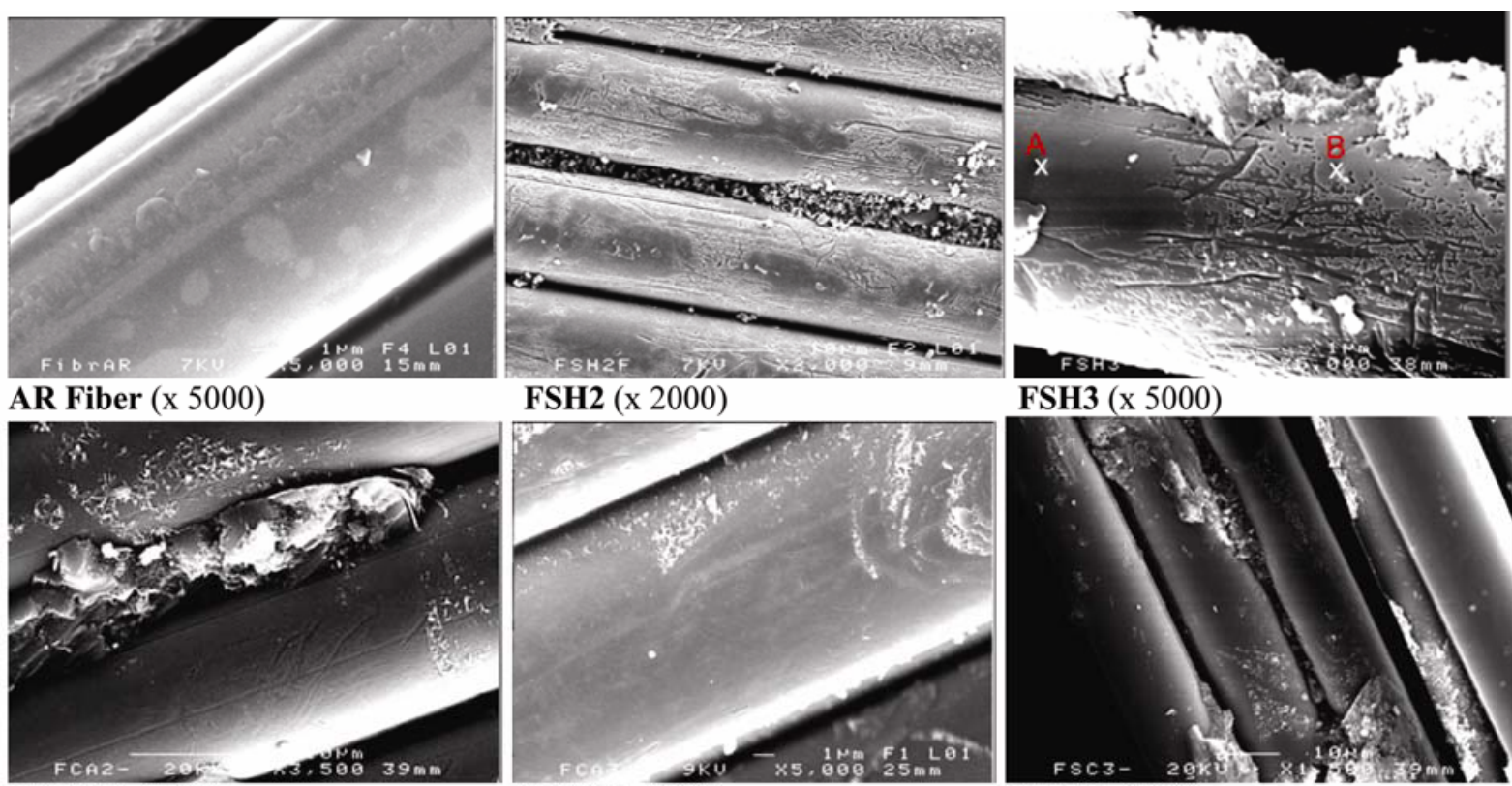

FCA2 (x 3500)

FCA3 (x 5000)

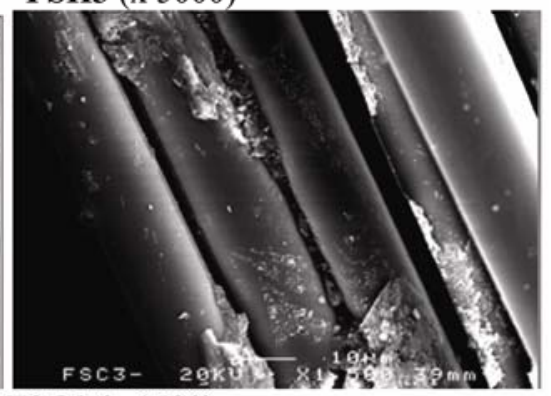

Figure 9. SEM observations of the fibre (AR) before mixing and of the glass fibres in the CEM II/B 32.5 cement matrix, conserved in different environments.

Table 6. Spectrometry X-ray analyses of the fibre body.

\begin{tabular}{|c|c|c|c|c|c|}
\hline \multirow[b]{2}{*}{ Element } & \multirow[b]{2}{*}{ Spectral type } & \multicolumn{2}{|c|}{ Point A } & \multicolumn{2}{|c|}{ Part B } \\
\hline & & Element (\%) & Atomique $(\%)$ & Element (\%) & Atomique $(\%)$ \\
\hline C K & ED & $4 \cdot 37$ & $9 \cdot 34$ & $6 \cdot 07$ & 11.63 \\
\hline $\mathrm{O} \quad \mathrm{K}$ & ED & $24 \cdot 52$ & $39 \cdot 37$ & $34 \cdot 39$ & $49 \cdot 50$ \\
\hline $\mathrm{Na} K$ & ED & 4.73 & $5 \cdot 29$ & $4 \cdot 87$ & 4.87 \\
\hline Al K & ED & $0 \cdot 34$ & $0 \cdot 32$ & $0 \cdot 35$ & $0 \cdot 30$ \\
\hline $\mathrm{Si} \quad \mathrm{K}$ & ED & 37.96 & 34.73 & $31 \cdot 60$ & 25.91 \\
\hline $\mathrm{S} \quad \mathrm{K}$ & ED & $-0.03 *$ & $-0.03 *$ & $0.13 *$ & $0.09 *$ \\
\hline $\mathrm{Ca} \mathrm{K}$ & ED & 8.41 & $5 \cdot 39$ & $6 \cdot 15$ & 3.53 \\
\hline $\mathrm{Fe} \quad \mathrm{K}$ & ED & $0 \cdot 22 *$ & $0 \cdot 10^{*}$ & $0 \cdot 11^{*}$ & $0.05^{*}$ \\
\hline $\mathrm{Zr} \quad \mathrm{L}$ & ED & $19 \cdot 50$ & $5 \cdot 49$ & $16 \cdot 34$ & $4 \cdot 12$ \\
\hline Total & & $100 \cdot 00$ & $100 \cdot 00$ & $100 \cdot 00$ & $100 \cdot 00$ \\
\hline
\end{tabular}

$*=<2 \sigma$

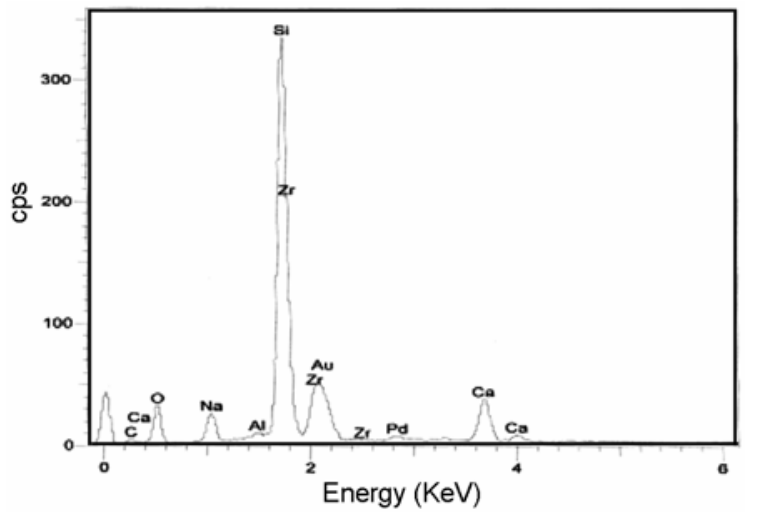

shows higher silica $(\mathrm{Si})$ contents than that detected at the point $\mathrm{B}$. On the point $\mathrm{B}$ the observed degradation is marked either by erosion or notches. According to the

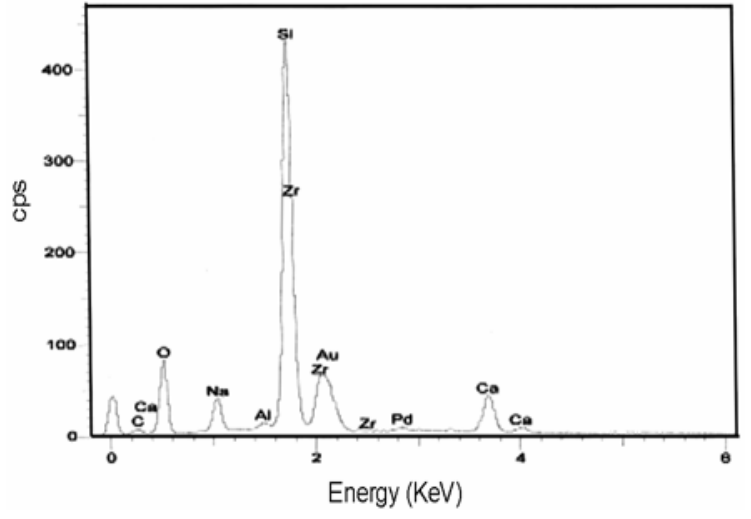

analysis, zirconium $(\mathrm{Zr})$, which is the protective element of the fibre, is higher at the point $A$ than that of the point B. The energy dispersive X-ray analysis of the glass fibre 


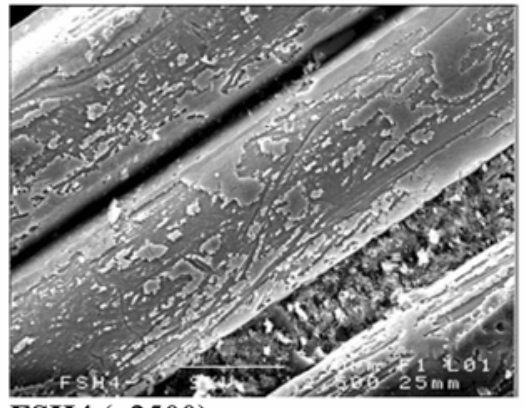

FSH4 $(x 2500)$

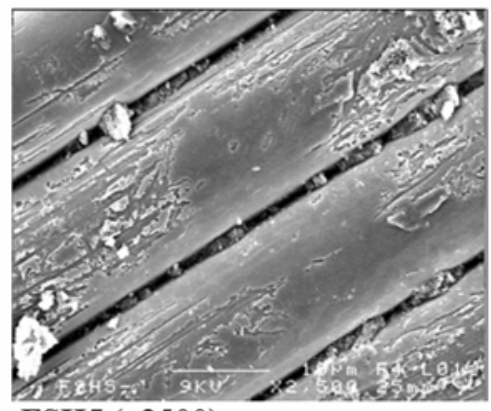

FSH5 (x2500)

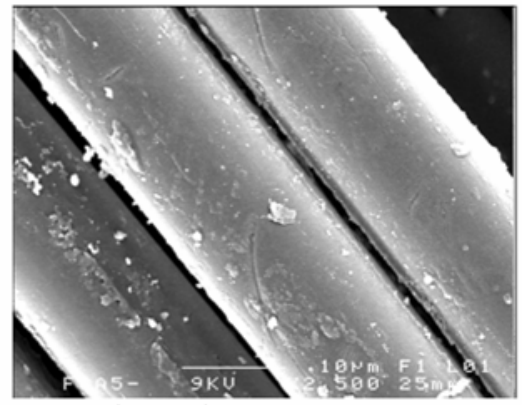

FCA5 (x2500)

Figure 10. SEM observations of fibres in a CEM I 52.5 cement matrix, conserved in different environments.

surface indicated that dissolution of silica from the glass surface occurred. The samples conserved at ambient air, FCA2 and FCA3, and in dry environment, FSC3, remain intact.

Those observations confirm the results obtained by $\mathrm{X}$-ray diffraction. First, silica fume additions permit to protect the fibres due to the pozzolanic reaction that transforms portlandite into CSH and thus decreases the matrix alkalinity. Second, the A-R glass fibre appearance remains stable in dry environment: on the one hand, $\mathrm{Ca}^{++}$ ion diffusion is restrained by a dry environment and the portlandite cannot develop. On the other hand, the carbonation, developed at the free surface of the samples, reduces the porosity.

Figure 10 shows the effect of a CEM I 52.5 cement on the fibres. The use of this cement amplifies the fibres degradation, as seen in FSH4 sample (as observed in the precedent samples made of CEM II cement, the fibres are ultra sensitive to a moist room). In the samples where silica fumes are added, the attack is less important and is not effective on the entire surface, which underlines the bad repartition of the silica fumes (see FSH5). Only samples conserved at ambient air, FCA5, display intact fibre surfaces. It must be noted that those fibres, announced alkali resistant by the manufacturers and introduced in a cement matrix containing up to $5 \%$ of silica fume, have however a low durability. It should be noted that CEM I 52.5 cement contains in his chemical composition higher quantities of free lime (free $\mathrm{CaO}$ ) and alkaline $\left(\mathrm{Na}_{2} \mathrm{O}\right)$ compared to the CEM II 32.5 cement. According to figure 11 it can be seen that the $\mathrm{pH}$ of the CEM I 52.5 cement is higher. The figure shows the $\mathrm{pH}$ values of pore solutions samples made from CEM II/B 32.5 and CEM I 52.5 . The $\mathrm{pH}$ values decrease when the conservation conditions change and the silica fume is added to the samples.

\section{Conclusions}

In this study, the obtained results permit to evaluate the behaviour of the alkali-resistant glass fibres used in a cement matrix and to observe the influence of the conservation environment.

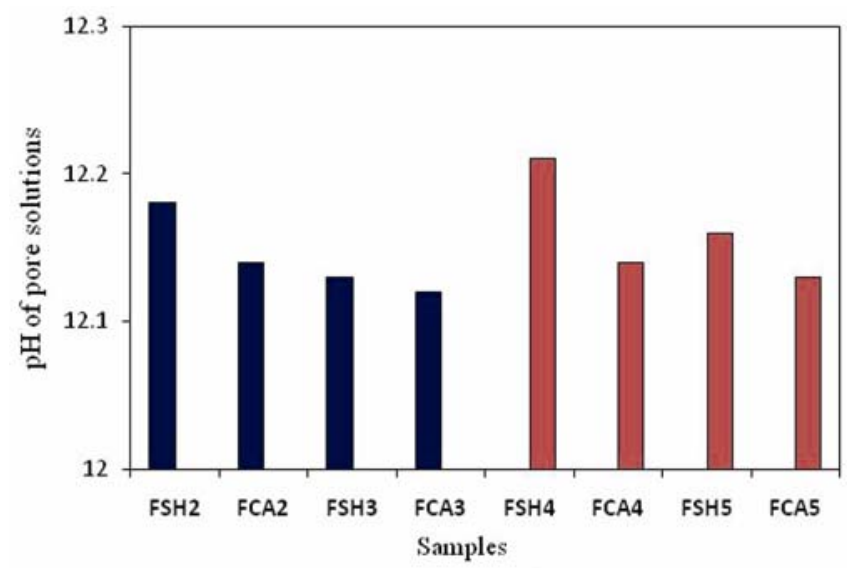

Figure 11. $\mathrm{pH}$ of pore solutions of the samples after 12 months of curing conditions.

The flexural strength drop is substantial during the first weeks of conservation and this is mainly related to the kinetics of cement hardening.

The addition of the silica fume at the rate of $3 \%$ contributes tardively to improve slightly the resistance, but does not give sufficient protection to the chemical attacks caused by alkaline environments on the fibres. This improvement becomes unperceivable at ambient air and dry environment conditions. However, this rate of silica fumes addition remains weak as amount to obtain of better results.

Under dry environment or low humidity, like a usual indoor building (case in ambient air), alkali-resistant fibres undergo surface modifications that look like disseminated spots. These degradations do not cast doubt on the structure stability of the glass fibre-reinforced cement.

On the contrary, the use of such materials in a humid environment (in moist room) has to be avoided. The stability of the structure would be endangered in spite of the fibre treatment and the silica fume use in the cement matrix.

The drop of flexural strength value is evident in ambient air and dry environment conservation conditions. How- 
ever, using SEM, no fibre deterioration has been observed. This shows indeed the complexity of the degradation phenomenon for the glass fibres in an alkaline medium.

If degradations seem to be inevitable, they are quite reduced by the use of fly ash containing cement (CEM II/B) in comparison with cement without additions (CEM I).

\section{Acknowledgement}

The author expresses his thanks to Joseph Le Lannic, CMEBA Rennes University, for his assistance with scanning electron microscopy.

\section{References}

Bentur A and Mindess S 2007 Fibre reinforced cementitious composites (London, New York: Taylor \& Francis) Ch. 8

Charles R J 1958 J. Appl. Phys. 291549

Cuypers H, Wastiels J, Van Itterbeeck P, De Bolster E, Orlowsky J and Rauoach M 2006 Composites: Part A 37 207

Daniel J I and Schultz D M 1986 Long-term strength durability of glass fibre reinforced concrete, Rilem Symposium, Sheffield

Gonenc O 2003 Durability and service life prediction of concrete reinforcing materials, Master Science Thesis, Department Civil and Environmental Engineering (University of Wisconsin-Madison)

Graham T G 2004 ACIMater. J. 2241

Gudmundsson G and Olafsson H 1999 Cem. Concr. Res. 29 1289

Hayashi M, Sato S and Fujii H 1985 Some ways to improve durability of GFRC, Proceedings Symposium on Durability of Glass-fibre Reinforced Concrete (Chicago: Prestressed Concrete Institute) p. 270
Kosa K, Naaman A E and Hansen W 1991 ACI Mater. J. 88 310

Krüger M, Reinhardt H W and Yong X 2003 Sulphoaluminate cement matrices used for textile and glass fibre reinforced concrete elements, International Workshop High Performance Fiber Reinforced Cement Composites (Rilem Publications SARL) p. 349

Kurihara T and Katawaki K 1989 Effects of moisture control and inhibition on alkali-silica Reaction, Proceeding of the 8th International Conference on Alkali-aggregate Reaction in Concrete, (Kyoto Japan) p. 629

Li Z, Liu A C P and Leung C K 2002 ACIMater. J. 206401

Majumbar A J and Walton P L 1991 ACI Mater. J. 126745

Marikunte S, Aldea C and Shah S P 1997 Adv. Cem. Mater. 5 100

Olafsson H 1986 The effect of relative humidity and temperature on alkali expansion of mortar bars, Proceedings of the 7th International Conference on Alkali-aggregates Reaction in Concrete (Ottawa Canada) p. 461

Paya J, Bonilla M, Borracheco M V, Monzo J, Peris-Mora E and Lalinde L F 2007 Waste Management 271416

Péra J and Ambroise J 2003 Cem. Concr. Res. 34671

Purnell P, Short N R, Page C L, Majumbar A J and Walton P L 1999 Composites: Part A 301073

Purnell P, Short N R and Page C L 2000 Composites: Part A 30 1777

Purnell P, Short N R, Page C L and Majumdar A J 2000 Cem. Concr. Res. 301747

Purnell P, Seneviratne A M G, Short N R and Page C L 2003 Composites: Part A $\mathbf{3 4} 1105$

Rols S, Ambroise J and Péra J 2000 ACI Mater. J. 192843

Schutte C L 1994 J. Mater. Sci. En. 13265

Shehata M H and Thomas M D A 2000 Cem. Concr. Res. 301063

Tomasawa F, Tamura K and Abe M 1989 Influence of water content of concrete on alkali-aggregate reaction, Proceedings of the 8th International Conference on Alkali-aggregate Reaction in Concrete (Kyoto Japan) p. 881

Xu G, Magnani S and Hannant D J 1998 Cem Conc Comp 2079 Yilmaz V T and Glasser F P 1992 ACI Mater. J. 1321151 